\title{
Multi-Agent Modelling and Renewable Resources Issues: The Relevance of Shared Representations for Interacting Agents
}

\author{
J. Rouchier, F. Bousquet ${ }^{2}$, O. Barreteau ${ }^{3}$, C. Le Page ${ }^{2}$, J.-L. Bonnefoy ${ }^{4}$ \\ Centre for Policy Modelling - Manchester Metropolitan University, UK \\ http://www.cpm.mmu.ac.uk/ juliette/ \\ j.rouchieremmu.ac.uk
}

\begin{abstract}
The issue that is addressed in this paper concerns the way interacting agents should understand their environment so that a common good used by the whole group would last. We synthesise the results of four models with agents interacting in artificial societies in which they have to share a resource. The four societies were built using multi-agent based simulation models that address issues related to the use of common renewable goods. The resources that are used by the artificial communities of agents are of two types: for some, agents must co-ordinate to exploit the resources; for others, the distribution of goods among agents is directly dependent on the distribution of the agents in space. But that classification cannot necessarily hold: the good use of the resources relies on an even distribution of agents in space, but this can be obtained with individual processes in some cases whereas in others it implies coordination too.
\end{abstract}

\section{Introduction}

\subsection{Issue}

The issue that is addressed in this paper concerns the way interacting agents should understand their environment so that a common good used by the whole group would last. This topic is related to fundamental issues in the two domains that we were addressing in our research: multi-agent systems and renewable resources economy. The "representations" we refer to in the paper are linked mainly to the definition of the Agents' research field: it is the understanding that the agent has of what it perceives, and that enables it to choose its actions.

The paper is based on results of simulations, made in multi-agent artificial societies [3], [10], [18]. In all the models the environment is a common good that the agents

${ }^{2}$ Cirad-Tera-Ere, Montpellier, France, bousquet; lepage @ cirad.fr

${ }^{3}$ Cemagref, Montpellier, France, barreteau@montpellier.cemagref.fr

${ }^{4}$ Université de Provence, France, Jean-Luc.Bonnefoy@up.univ-aix.fr 
have to use to survive. Because the models were realised by different people, they not only describe different case studies but they also exhibit different theoretical approaches to the issue. They are all gathered here because the building of specific representations for agents in relation to an evolving environment was their common, main question. In all of them there was a serious concern that one should model individual representations of the environment so that the agents display some expected global behaviours. The most important issue was then to know how much the agents should share in these representations. A "representation" is here the value that an agent has of an action it could undertake on its environment in a distributed way: should it use or not some elements of its environment. What interests us here especially is the idea that the agents have of what is attracting for them: should they all agree, or have very different approaches to the same object or agent?

\subsection{Theory and Tools}

A usual approach to the "best way" to use a resource in the main stream of ecological economics, is to consider that the necessary exchanges of goods are going to lead to an equilibrium that imply a good use of the resource. In that case, what is important is that the agents produce different goods and are interested in getting different ones, too, and thus that they are willing to exchange [8].

In a multi agent system, agents can have their own representations of the world, evolving independently of the representations of the others, and deduced from their interactions with other agents and the actions of those other agents. Alternatively, it is possible to impose some shared representation, where the agents always behave according to norms and common habits. Actually, the majority of the research in the field of MAS for collective actions deals with joint beliefs, joint intentions and joint commitment [12] In order to solve complex tasks in common, the underlying assumption is that agents must share a common representation of the problem even though they have different roles [7].

\subsection{Applications}

In our applications, the representations are the information that the agents use to choose their actions concerning the common resource and the other agents. In all cases, the agents have an individual representation of their environment and there can exist a common representation. The individual representation of the agents can be close to or different from the common one; it can evolve in an endogenous way or be stable in the model.

As a first analysis, the different models give results that could seem to be quite contradictory: in three models the agents must have different evaluations of the same resource so that the global dynamics is sustainable; in the other, only common points of view can insure a good use of the environment. That is the reason why we had to look for a more global explanation. The assumption was that it was the characteristics of the resource that would explain that difference.

The models describe several kinds of goods and resources: 
- In Shadoc the agents use an irrigated system to water their field. They must first secure their access to credit and then their access to water to keep cultivating from one time-step to another.

- Djemiong, where agents have to hunt in a forest. They can gather in groups or decide to act individually. The sustainability of the use of the resource is then studied depending on the way they all act.

- JuMel describes the use of grazing lands by mobile herders performing exchanges of goods with farmers so that to get access to pastures and water. All exchanges are made among individuals through negotiations.

- CommonForest describes a community where each agent has her cattle graze in a forest. There is a common decision that spots the places to protect, and the agents have the choice to obey to that common prescription, or to behave like they individually want to.

In Shadoc, the agents share a common production tool and thus require a common representation to use this tool in common for a long time. For two models where resource is distributed, we show that the agents must have heterogeneous representations if the resource is to be used in a sustainable way. In the last model the agents have an homogenous point of view of what their actions must be, but the individual evaluation of the resource (the representation they have of it) differs a lot among them. This indicates that the best way to model the agents' representation of the environment is related to the way the production itself is represented, and this choice is of course directly related to the type of resources that are studied.

\section{Models}

In this section we present all four models, describing the context of their building, what an agent is in each, what kind of representation it has of its surroundings and of the other agents. A short analysis of the results is then presented.

\subsection{Shadoc: a Conscious Co-ordination of Actions}

Context. The first model, Shadoc, represents a community of farmers using an irrigated scheme [1]. It was built so that to investigate why most irrigated systems in the Senegal River middle valley are underused relative to their design capacities. An irrigated system, as it has been observed during the field study that led to building of the model, is a network of canals that bring water from a source to plots for agricultural production by farmers. These farmers are grouped into producer organizations, and trade between themselves and with other people out of the system; the whole may or may not be managed by a users' association.

There are different levels of complexity in the description of the system. First, the ecological system in itself is not out of one piece: the water that is pumped from the river has to be taken in charge by a lot of different actors along the time. Then the relationship among the different actors are not simple: each one is included into different groups, interconnected through membership and service relations and in addition to this complexity due to their nature, these systems are also the reflection of 
complex social relationships. Complexity also arises out of the need for some actors to wait until others have performed a particular task before they can take action. For example, a farmer must wait until the pumps are turned on before he can start work in this plot, but, in some systems, the pumps are not turned on until enough farmers are ready to begin.

Agents and Representations. This model is based upon certain assumptions. Basically we assume that irrigated systems may be represented as a place of acquisition and distribution of two resources: water and credit. The PumpStation allows the access to the shared good, water. The quantity of water depends on the functioning state of that PumpStation and on the choice of operating rule made by the agents. The agents in the model stand for different organisational levels: some are individual actors (farmers) and others are groups [17]. Simulated society is assumed to be structured with only three types of irrigated system related groups described below, one friendship network, the archetype of all existing networks, and a four-level social categorization.

Each farmer agent belongs to three different kinds of group agent:

- $\quad$ one whose grounds attribute is \#waterAllocation among farmer agents with their plot attribute along the same Watercourse instance,

- $\quad$ one whose grounds attribute is \#pumpStation management. This group agent includes all farmer agents of the scheme represented,

- one whose grounds attribute is \#creditAccess for its members, which composition is a priori different to the composition of \#waterAllocation group agents.

Each farmer agent acts also according to his own goal attribute from the set \{\#production, \#food, \#land, \#waitingBetter\}. Each agent has also its own point of view about the state of the system and especially its potential relations with other agents. This representation contains his knowledge of the water level on his plot, his friendship network constituted by other farmer agents with which it will be willing to cooperate through exchange of information or services and finally assumed rules enforced by agents with which it is in relation.

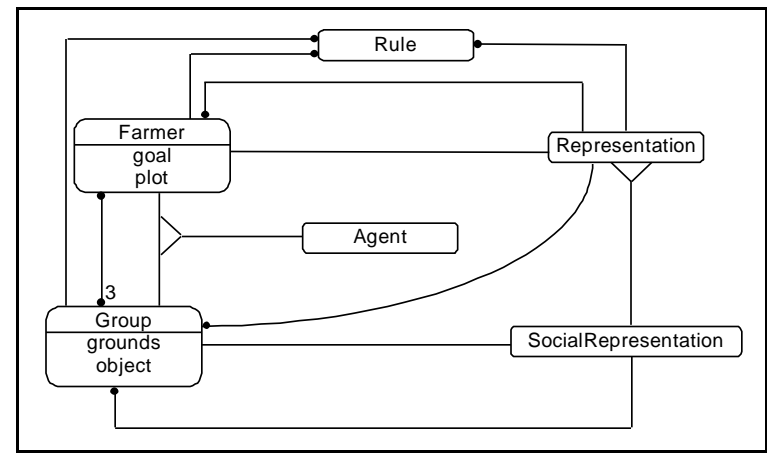

Fig. 1. Social structure of the Shadoc model. 
The Farmer and Group classes both inherit from the Agent class. Each Farmer class instance is in relation with exactly three instances of the Group class, one instance of the Representation class (which inherits from the SocialRepresentation class) and several Rule class instances. Each Group class instance is in relation with several Farmer class instances, several Rule class instances and exactly one SocialRepresentation class instance. Each Representation class instance is in relation with several Rule class instances, several Farmer class instances and several Group class instances.

Plot sowing divides the irrigation stage into two steps for each farmer. Initially, the purpose is to get information about the start-up of the pump station, either from a farmer in the friendship network or from the pumping grounds group. When it gets this information, it updates his representation of pump station functioning state and seeks for sowing his plot. Then, at each time step, the farmer-agent has to choose to go or not to go to the field, depending on its goal and its representation of the plot water level and pipe state, pump station functioning state and the possibility of getting water. At the same time, pump station management group updates at each time step its representation of irrigated scheme state and, according to the fulfilment of its rule of ending cropping season, it uses its representation to stop pump station. Then each agent switches to third stage: each one evaluates its satisfaction criterion. If satisfied, it changes nothing in its rules. If not satisfied, it may change its goal and its set of rules according to one of the following methods:

- changes nothing,

- imitates the agent of its "imitation group" with better score for its own criterion,

- selects agents of its "imitation group" who would have satisfied its criterion and imitates the one with the behaviour nearest to its own,

- imitates the agents who got the best result for a fixed time and then reverts to his former behaviour if not satisfied.

For each farmer, the "imitation group" is the group of farmers from which it may collect information (also called in this version of model its "friendship network") and to which he thinks it is worthwhile to compare itself. This may take different forms for each farmer:

- The whole friendship network,

- the intersection of the friendship network with the water allocation group,

- the intersection of the friendship network with the credit access group,

- the intersection of friendship network and water allocation group and credit access group.

For each group, the "imitation group" is the set of all other groups with same grounds. In imitating another agent, any agent adopts the whole set of rules of this agent for itself.

Simulations: Influence of Social Networks on Irrigation Schemes. The influence of social networks on the viability of irrigated schemes has been tested. A simulation is considered to be viable if it lasts more than four cropping seasons with at least one cropping season after the fifth one practiced by more than $20 \%$ of Farmer agents. There are several varying parameters: 
- "homogeneity". If this parameter has a "true" value, \#creditAccess group agents and friendship networks have the same composition as \#waterAllocation group agents. Otherwise these group agents are $a$ priori independent,

- number of friendship networks,

- vector with percentage of farmer agents for each mode of imitation set constitution.

What the results show is that even if social networks cannot be used to explain the viability of some scenarios, the number of friendship networks still has an effect: the less divided the population, the more viable the irrigated system. That means, unsurprisingly, that for one scenario, the reduction in the number of friendship networks raises the probability of viability of a simulation, in other words, the more people get along the higher the probability of viability of a simulation for a given scenario.

A population of farmers with imitation sets limited to farmers along the same watercourse seems here to be another factor raising the probability of viability for a simulation of a given scenario.

Finally, the homogeneity parameter seems to have no effect according to Table 1 which compares mean frequencies of viable simulations for each homogeneity value, the number of friendship groups being fixed at 5 and imitation sets varying.

Conclusion. This first experiment shows that viability of irrigation systems is enhanced when more people accept to share their knowledge about this system. Furthermore: the more these people are connected through the resource, the greater the effect.

\subsection{JuMel: Emergence of Heterogeneity}

Context. The model was built as part of a study on cattle transhumance in the extreme North of Cameroon. In the soudanian zone, the resource is highly irregular and herdsmen have to travel with their cows to feed them easily, sometimes for long time-periods. Thus, they leave their usual homes and perform movements that are called transhumance. Although the land seems to be open [13] there exist unwritten rules that define how these "commons" should be used [15]. During a field study, an economic analysis was aimed at finding these rules. It showed that, at one moment, the choices were based as much on the individual relationships with local people as on the grazing patterns. More specifically, it was shown that these relationships show great regularity [16]. To interpret this regularity, it is possible to refer to the different economic models: some consider that any action can be interpreted as a cost, and that regularity, creating familiarity, is a good way to reduce transaction costs [14], [21]. But it is also possible to regard the relation as an element that is important in itself, and that the agents want to preserve the history of their interactions thanks to that regularity [11]. The image that each one has of the others, the way it is built and how it influences the actions, seemed to be an interesting way to question the economic habits of the transhumant people [18], [19].

The aim of our research was to analyse the use of the resources and the patterns of relations that could be created simply through merchant exchanges, in an artificial world that captures the situation of herdsmen trying to have access to a resource over 
time. To build the agents' logic, the inspiration came from the economic points of view previously described, and two ways of reasoning were implemented for our agents: one inspired by the idea of cost, and the other by the idea of institutions.

Since we wanted to generate regularities in relationships, the choice was to decide that the farmer who expressed a refusal would be made somehow unattractive. This was translated, using no more than the minimum cognitive processes:

- To capture the idea of costs: the herdsman integrates any refusal as an extra-cost anticipated for the new transaction.

- To capture the idea of a value in the relation: the herdsman remembers the refusals and the agreements made by the farmers.

Agents and Representations. We put together three classes of agents (Figure 2). The first population represents herdsmen who need the grass and water and request access by making proposals. The second represents the village chiefs who accept the presence of the herdsmen by providing good or poor access to water depending on their order of arrival. The third is that of the farmers who are grouped together in villages under the responsibility of the village chiefs and who own land that they may allow herdsmen to graze.

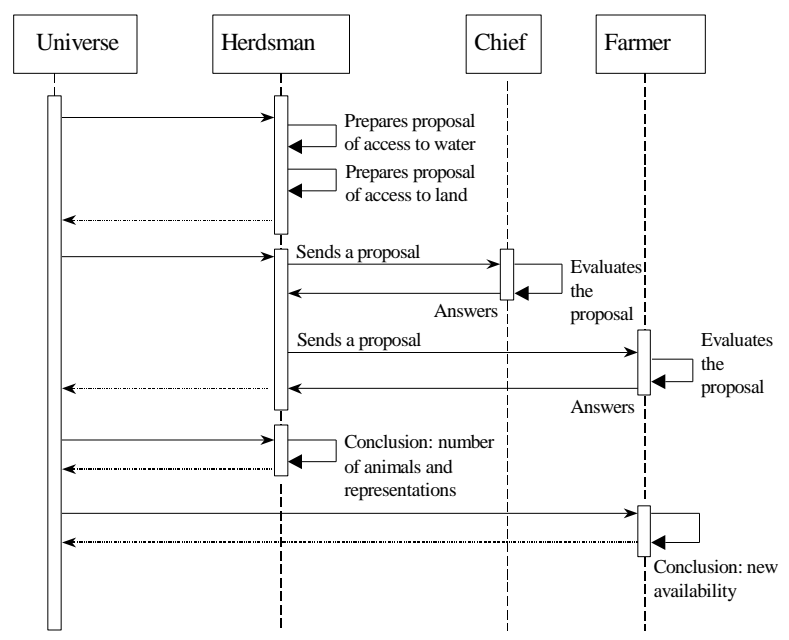

Fig. 2. A simulation step

The representation is based on the past exchanges between the herdsmen and the farmers. A farmer always charges the same fee when he allows a herdsman onto his land. A village always charges the same amount for a good site but accepts whatever the herdsman offers for a poor site. To start with, the herdsmen do not know the value of any of the access fees. When a farmer accepts an agreement or when a village provides access to a good site, the herdsman registers the cost of the transaction as a representation of the other agent. Any time the herder receives a refusal from a farmer or when a village provides access to a poor site, the representation (the access fee he is willing to pay) changes: it is increased by the « learning constant ». The herdsmen also remember the "quality of the relation" which is: 
number of good accesses - number of bad accesses (for a chief)

number of proposal accepted - number of refusals (for a farmer)

In the experiments described here, there are two possibilities available to the herdsmen for choosing which village chiefs and farmers to ask for access:

- The first option is to choose the «cheapest» village, and address a demand to its chief. Since the agent will have to pay for the fee of the chief and for two other agents, the imagined cost for a village has a value of:

Village price $=$ the chief fee $+2 *$ (average of representations of known farmers in the village).

Once the villages with the lowest fees are chosen, then the herdsmen choose the cheapest farmers in each village. As the herdsmen do not know the fees a priori, when they make this choice they can only ask the agents that they already know.

- The second option is to choose the village where he had the largest excess of compared over refusals. The global indicator for the village is:

Village's indicator $=($ "quality of relation" with the chief $)+($ average of "quality of relation" with the farmers of the village)

Then he addresses the chief, and in the village he asks the farmers that have the highest quality of relation.

Conclusion. In the results (Figure 3) one notices that the resource is highly depleted, and then the herds are quite small when the agents choose with the "cost priority" choice, whereas it is almost at its best when then choose with "friend priority". Indeed, the "cost priority" representation creates a very important competition among the herdsmen.
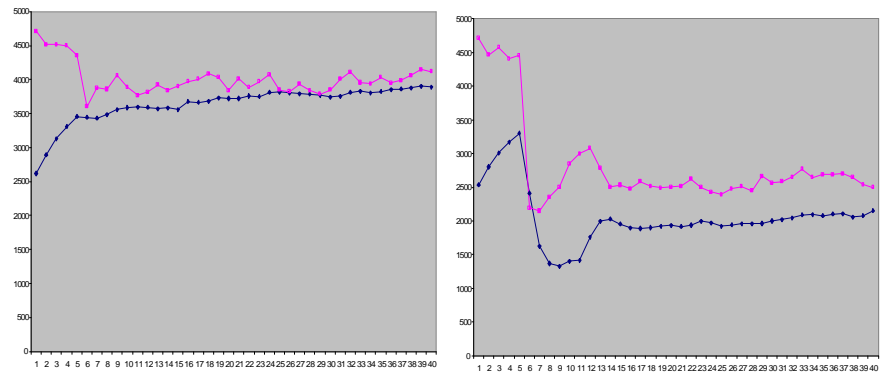

Fig. 3. Total number of animals in the environment and total number that could be accepted as a maximum by the resource along the time (400 time steps). On the left, the choice is made with "friend priority": the resource is not too depleted compared to the beginning, and is quite well used. On the right, the choice is made with "cost priority", which is bad for the resource, and where it is not so well used. 
One can see that usually in the "friend priority" choices, each transhumant has a different way of classifying the agents that are the most interesting to it. That difference of classification can be explained by the fact that the agents' representations are based on individual criteria (the quality of the relationship) in the "friend priority" cases whereas they are based on objective criteria (real prices) in the "cost priority" ones. Indeed, with the "friend priority" mechanism, the agents remember the history of their encounters, which unable them to develop representation that are all original; on the opposite, with "cost priority", they have more chance to share interest for the same farmers.

If one observes the error of the agents, this error being for one agent the sum of the differences between its representation of the price and the real price for all farmers he knows. In the cost priority simulations, this error is what creates the individual representation of the agents since it is the only difference of representation between all of them. One observes then in "cost priority" simulations, when one varies different initial parameters, that there is a high correlation between the mistakes that the agents make in the evaluation of the prices and the survival: the highest the mistake, the better the results.

That correlation of "having heterogeneous representation" and having a good use of the resource is just related to the definition of the access. In the model, a limited number of animals can be accepted on the fields. The results show that the resource is much less depleted in that case if not all the agents regard the same places as attractive, like in the "cost priority" simulations. If all transhumant are tempted to ask to the same farmers, only a few of them won't be refused and the resource will have a high chance to receive too many animals.

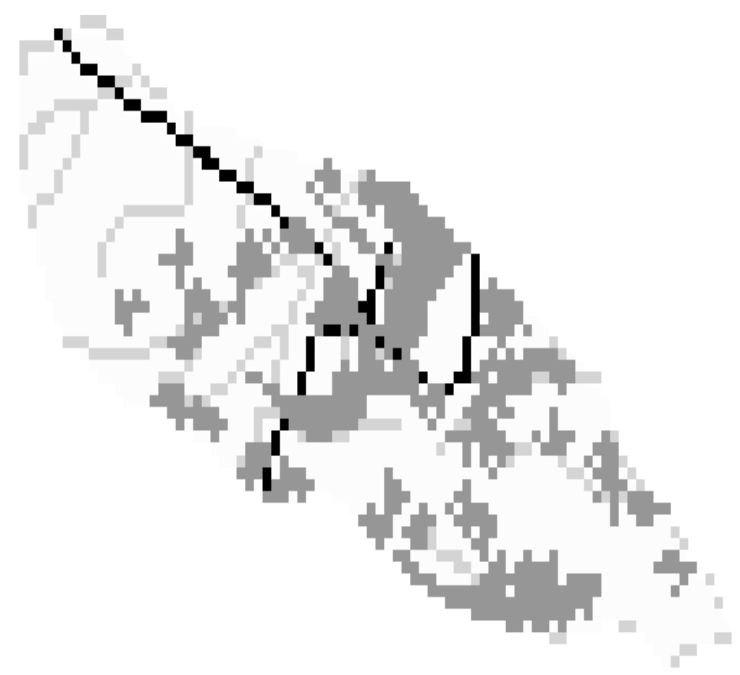

Fig. 4. Locations of the traps' paths on the spatial grid for experiments R1 and R2. The first layer, (slight grey), represents standard cells. The second layer is the presence of water (medium grey), the third one is the presence of road (in black), and the last one (dark grey) is the presence of traps. 
In our study, having heterogeneous individual representation to perform action is what allows the agents not to create competition that depletes the resource.

\subsection{Spatial Representation and Groups Coordination: Djemiong Model}

Context. This example is based on a study held in an eastern Cameroonian forest village named Djemiong. In that area where there exists no protected area, the challenge is to understand how the resource is managed locally. The aim of the research is to elaborate a model in order to study the viability of this management scheme. The major hunted specie is the blue duiker (Cephalophus monticola, Thunberg). Surveys have been conducted to understand the hunting behaviour of the inhabitants [20].

In the Djemiong village, the resource is hunted six months/year and there is a spatial shifting rule. Each year each hunter changes the location of his traps. The hunters present this behaviour as a management rule. Can the rules regulating the access to space at different moments of the year be considered as a management rule? This is the key-question of this study. Consequently, we need a spatial and dynamic simulation of the resource component, but we also need to take into account the behaviour of the hunters, the way they interact when they decide to locate their traps on the village's territory.

Data has been collected to simulate the life history of the blue duiker. A duiker agent has been created. Its attributes are the age, the sex, the gestation length and the partner. The behaviour of the blue duiker is implemented through one method that uses the above life-history parameters to define, with a weekly time-step, the growth, mortality, and reproduction functions, and also some rules for the movements [4].

Agents and Representations. 90 hunters agents have been created. By simulation we first studied the scale of the agents' spatial representation: their representation concerns the space, which is represented at various scales. The lower scale is the elementary cell of the resource model. The intermediate level is the path level: each agents knows the positions of trap paths which is composed of eight elementary cells. The upper level is an area limited by rivers and roads. In a first set of simulation it has been demonstrated that the relevant representation for the agents is the intermediate level, the traps path.

We also simulated the co-ordination of the agents: each agent has a collection of 4 precise traps' paths, which is randomly initialised from a set of 4 hunting localities. A first scenario, denoted $\mathrm{H} 1$, states that a hunter agent chooses its current traps' path randomly among the 3 one he was not using during the previous season. This scenario stands for individual turnovers without any coordination between the hunters. To account for such a process, a second experiment (H2) defines 30 groups of 3 hunter agents. The 4 precise traps' paths are assigned to these collective entities that may represent kinship networks of hunters from the same family. The individual turnovers' rule also applies here, but with an additional constraint: a traps' path remains not hunted by any of the 3 group's members during 3 successive seasons. 
Table 1. Global results for the second set of experiments (with hunter-agents).

\begin{tabular}{|c|c|c|c|}
\hline Experiments & $\begin{array}{l}\text { Hunting } \\
\text { coverage } \\
\text { (cells' } \\
\text { number) }\end{array}$ & $\begin{array}{l}\text { Population } \\
\text { density } \\
\text { after } 25 \text { years } \\
\text { (number of } \\
\text { animals } / \mathrm{km}^{2} \text { ) }\end{array}$ & $\begin{array}{l}\text { Total } \\
\text { catches } \\
\text { during } 25 \\
\text { years } \\
\text { (number of } \\
\text { animals) } \\
\end{array}$ \\
\hline $\begin{array}{l}\text { H1 } \\
\text { Hunters' } \\
\text { periodic } \\
\text { individual } \\
\text { turnovers }\end{array}$ & $\begin{array}{l}640.8 \\
(28.4)^{*}\end{array}$ & $15.77(3.4)$ & $\begin{array}{l}12073.7 \\
(766.1)\end{array}$ \\
\hline $\begin{array}{l}\mathrm{H} 2 \\
\text { Hunters' } \\
\text { periodic } \\
\text { collective } \\
\text { turnovers }\end{array}$ & $\begin{array}{l}747.2 \\
(26.5)^{*}\end{array}$ & $24.21(3.4)$ & $\begin{array}{l}13970.3 \\
(824.3)\end{array}$ \\
\hline
\end{tabular}

For the second set of experiment, we can see that the H1 scenario is the worse: after 25 years, the population and the captures are still decreasing. The low value for the hunting coverage (table 4) suggests that there is probably a problem of spatial congestion ( $90 * 4=360$ individual traps' paths have to be defined, some of them should overlap, and then all the hunter agents could not access to their path if it is already occupied by others). There is probably another reason to explain the difference of about 9 animals per $\mathrm{Km}^{2}$ with the population density of $\mathrm{H} 2$ (table 4). The lack of co-ordination between the hunter agents for scenario H1 should erase the effect of the individual turnovers.

Conclusion. In Djemiong village it has been observed that places are inherited in the families. By inheriting parts of the village area from their fathers, hunters take their decisions of traps locations on a partial representation. Thus, the management of the resource is more complex than imagined: it has to be understood through the links between social organisation and spatial structure. Dealing with that complexity, multiagent simulation is used to identify the relevant organisation level (groups rather than individuals), the relevant spatial scale (path rather than hunting localities) and how the agents co-ordinate to avoid competition.

\subsection{Spatial Representation and Collective Decision: CommonForest.}

Context. This model is a theoretical one that tends to question issues from the field of geography [2]. In this model, agents use a resource, and for that can take collective decisions so that not to deplete it. Herder agents will forage in a fragmented landscape composed of several forests. A model of forest diffusion provokes an increase of the 
forest cover. The herds consume the forested cells of the spatial grid. Agents have individual representations of the space they share and act according to that representation.

Agents and Representations. The herder agent memorises each cell it has foraged and the state of the cell at that moment. At any time step the agent uses a specific threshold to decide if it grazes or not: if the group of forest cell is bigger than the threshold it uses, it is free to use the forest. The individual representation of space is simple: rather than a mental map composed of a visited cells array, the representation is the sum of states of forest cells they have encountered. It helps to decide of the individual threshold: the more forest cells the agent meets, the more abundant the forest seems to be and the lower the threshold. That representation is periodically compared with others' perceptions to build a collective threshold that is computed at the village level. The village entity is the group of agents that defines a collective threshold to constrain the consumption. For that, the forests which size is under the collective threshold will be protected against consumption.

Three strategies are defined.

- The first one is called individual strategy. The agent does not take into account the collective constraint and acts according to its individual representation.

- The second one is called collective strategy. The agent will respect the rules imposed by the group and avoid the protected forests.

- The third strategy is a mixed strategy. In case of conflict between the individual and the collective representation, the agent will compute a mean threshold.

The goal of the simulations is to compare the three strategies. The initial state of the landscape is presented in figure 5. Periodically the contiguous cells are aggregated in a forest entity. Depending on the collective threshold this forest is marked as protected or not. In that case the cells will be protected against the strategy 2 agents. With the strategy 1 and strategy 3 , agents decide by themselves if they consume that resource. 


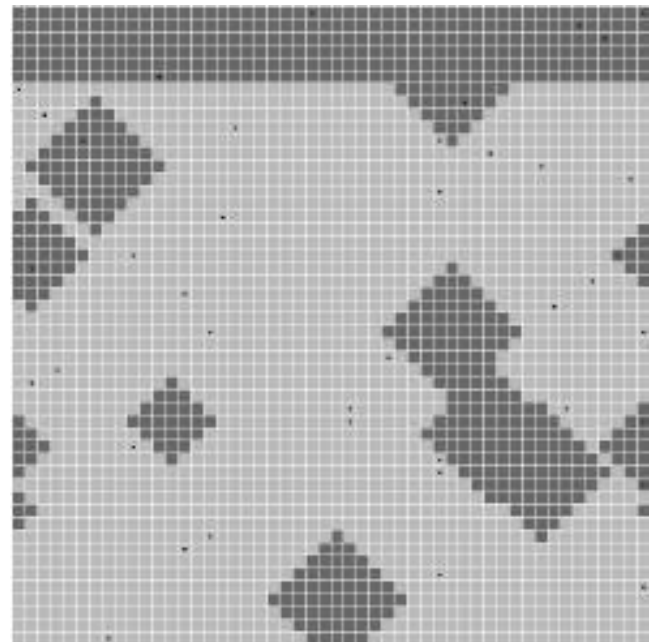

Fig. 5: initial state. The forest is represented in dark grey (686 cells grouped into 11 forests). Herder- agents are represented by a dot. The whole landscape is made of $50 * 50=2500$ cells with closed boundaries and Moore neighbourhood.

Before the comparison of the three strategies we have tested a scenario without any representation. As a result the forest always disappears between time step 150 and time step 250.

The first scenario tests the individual strategy. Each herder agent will decide which forest it will consume depending on its past history. The maximum value of the threshold is 10 . For a period of ten time steps the agent will move and decrease its threshold each time it is placed on a forested cell. If the agent has encountered few forested cells in the past ten time-steps, its individual threshold will be high and thus larger forests will be protected.

The second scenario tests the collective strategy and the third scenario tests the mixed strategy.

Table 2. Simulation results. These results are given for 300 time steps simulations

\begin{tabular}{|l|c|c|c|}
\hline Strategy & $\begin{array}{l}\text { Forested } \\
\text { cells }\end{array}$ & $\begin{array}{l}\text { Number of } \\
\text { forests }\end{array}$ & $\begin{array}{l}\text { Mean } \\
\text { threshold }\end{array}$ \\
\hline Individual & 150 & 20 & 8 \\
\hline Collective & 230 & 61 & 5 \\
\hline Mixed & 233 & 63 & 6 \\
\hline
\end{tabular}




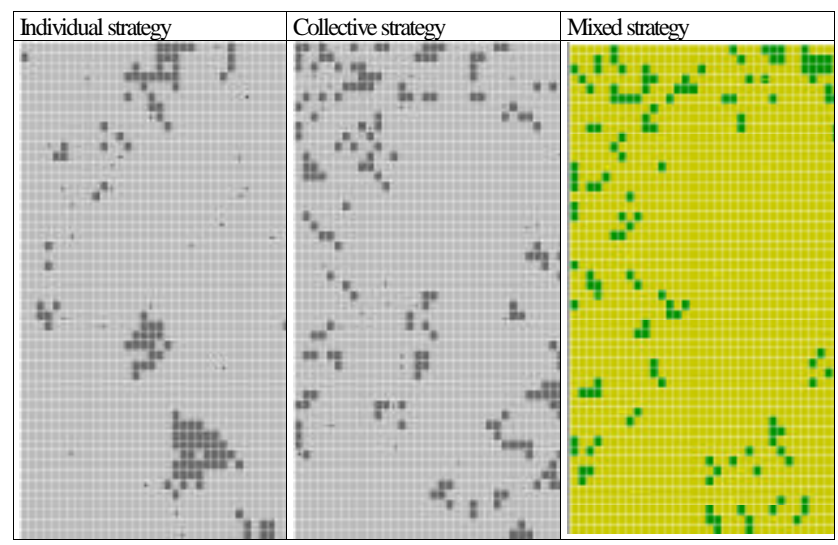

Fig. 6: Landscape state after 300 time steps

One can observe the individual strategy gives the worse results both in terms of resource preservation (the forested cells indicator is the worse) and in terms of agent satisfaction. The threshold gives a good measure of the agents' satisfaction. The less the agents finds resource the highest its threshold is. The landscape state (figure 6) is also very different. The individual strategy leads to larger forests and the collective norm leads to more fragmented landscapes with more resources. Figure 7 shows that the scenario with collective decisions shows the greatest heterogeneity of the representations. The interpretation is that the distribution of the resources leads to diverse local histories of the agents. While foraging some succeed and some fail. The individual scenario is more homogenous, probably because of the lack of resource. There are minor differences between the collective strategy and the mixed strategy. By repeating the simulations, we observe that the mixed strategy gives more variability in the results. 


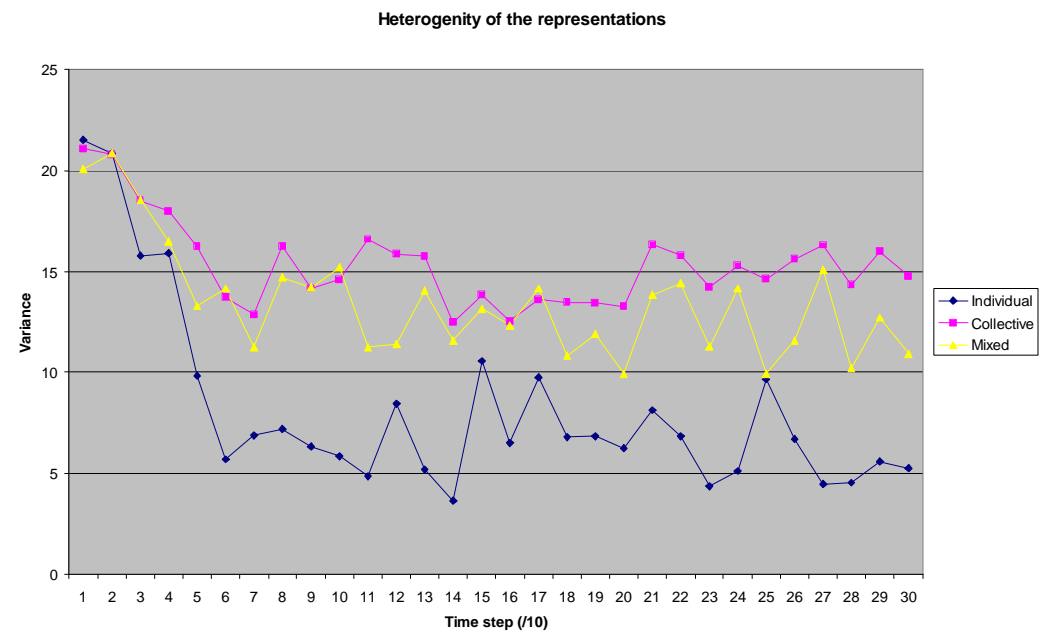

Figure 7: Heterogeneity of the representations. The values represent the inter-individual variability of threshold value. The difference is the most important when the individual all agree on the threshold for action and is equivalent when they have a mixed strategy. The representation is however much more homogenous when they all act in an individual way.

Conclusion. The purpose was here a theoretical one: we wanted to study the links between a dynamical landscape and the actions of the agents that depend on their representations. In that exercise, they can act accordingly to a common norm, which is called a common threshold or according to their individual threshold. In any case they keep their own individual point of view on the resource. What is shown is that as long as it comes to protection of the resource, the result is much better when the agents share their criterion of the choice of protecting or using the resource. What appears however is that the heterogeneity of individual representations for the state of the forest is all the more important than the choice is common and the resource protected.

\section{Discussion}

The four models presented here were created to tackle different case studies that deal with the use of renewable resources among agents. The representation formed by the agents about the resource reveals itself as important as we had imagined when deciding to focus on that aspect. What is pretty clear in our results is that competition has a bad impact on the production. This is an assumption that is often put forward by the people who try to create artificial societies [6]. But it is usually accepted that the agents have to agree on their representations so that one can observe a noncompetitive behaviour [5], [12]. This is not necessarily what our results show. 
In each case described the individual representation that exists for each agent is more or less related to the representation of the others. Homogeneity of representation can be good for the resource and the society of agents in some cases. This was very clear for one of the models, Shadoc, where the system would work better when the agents have homogenous representations of the actions to undertake. In another, CommonForest, if the agents agree on the representation they must choose for action, the resource is less depleted, but on the other hand the individual representation of the resource gets much more heterogeneous. For the other models, it is clearer: only a high difference of perception among the agents can secure the sustainability of the system. This appearance of contradiction is interesting since it questions the a priori put in the description of the systems.

In the Shadoc model all the agents should share a common knowledge and common rules so that the system can work better. Actually the resource is here described right away as a production tool where a very high degree of co-operation is needed. That co-operation is very simple, but it is anyway put into the system at first. As a direct consequence, the agents cannot all have the same activity and this forces them to agree at least partially on their representations. If there is not that minimum degree of agreement, the agents are not even able to use that resource.

In CommonForest, one sees that the homogeneity of actions is important. But actually, it is not a homogeneity of actions to perform that is fundamental, but the agreement on the actions that must not be performed. The common protection of certain places leaves the agents free to act in an independent way and they acquire, as a result, very different points of view on the resource. The more they agree on action, the more they disagree on their perception.

In the two other models, the homogeneity of representation is damageable for the resource. It is true when the representation depicted is fixed (Djemiong) and embedded in the social structure as well as when it emerges from the interactions (Jumel). In these cases, the fact that agents disagree, or have a false representation of the environment is the very element that makes the system sustainable, and this is for cases that seem to be quite usual in the world: when resources can be obtained by any individual agent that arrives first. This can be somehow related to the idea that some misunderstanding can be a key element of the building of a social group [9].

To be able to synthesize these results, it seemed interesting to draw two categories for the resource. In some cases, it is interesting to point out that the agents need to coordinate to get goods and that the resource can be considered as produced by them in an active way: for that then they must gather at some occasion and it is better if they agree on some common representation of the world. In other cases, one can consider that the allocation depends on the repartition of the agents in space and requires an even distribution, and it is then better for them not to be interested by the same goods. In that case, we saw two good ways to picture it: either to give to the agents a representation that make them consider different spaces as good for them, or to make them agree on the places they should avoid.

What we conclude is that there is not necessarily one good solution to co-ordinate agents using a common good. The agents do not necessarily have to co-ordinate when they share the same place and/or the same resource: the need of coordination depends directly on the way the system is built and on the type of resource that one wants to describe. Before a choice of representation has to be made the very dynamics of 
action and resources are to be considered. Some misunderstanding among the agents can reveal itself very useful for the system.

This can be applied to the analysis of real systems (like in our simulation studies), but can reveal itself interesting for all people who have to create a system and organise the agents. If some elements that have to be used will be limited in the system, the way that resource will have to be implemented can be thought as competitive (or not), in which case the system would be optimal with agents that are heterogeneous in their representations.

\section{Acknowledgements}

Cirad supported the building of these models and the simulations that were led.

\section{References}

1. Barreteau, O., Bousquet, F.: Shadoc: a multi-agent system to tackle viability of irrigated system. In: Annals of Operation research, Vol. 94 (2000) 139-162

2. Bonnefoy, J.L., Le Page, C., Rouchier, J., Bousquet, F.: Modelling spatial practices and social representations of space using multi-agent systems. In: Ballot, G., Weisbuch, G (eds) Applications of simulation to social sciences. Hermes (2000)

3. Bousquet, F.: Distributed artificial intelligence and object-oriented modelling of a fishery. In: Mathematical Computer Modelling, Vol. 2018 (1994) 97-107

4. Bousquet F., Le Page C., Bakam I., Takforyan A: A spatially explicit individual-based model of blue duikers population dynamics: multi-agent simulation of bushmeat hunting in an eastern cameroonian village. In: Ecological Modelling, in press (2000)

5. Conte, R., Castelfranchi, C.: Mind is not enough: the precognitive bases of social interaction. In: Gilbert, N., DOran, J.(eds), Simulating societies, UCL Press (1994) 267-286

6. Conte, R., Gilbert, N.: Computer Simulation for Social Theory. In: Conte, R., Gilbert, N. (eds) Artificial Societies. The Computer Simulation of Social Life, UCL Press, London (1995) 1-15

7. Conte, R., Castelfranchi C.: Distributed artificial intelligence and social science : critical issues. In: O'Hare, G.M.P., Jennings, N.R. (eds.), Foundations in Distributed Artificial Intelligence, Wiley Intersciences Publications (1996) 527-542

8. Costanza R.: What is ecological economics ?. In: Hall, C.A.S. (ed) Maximum power, the ideas and applications of H.T. Odum, University Press of Colorado (1995) 161-163

9. Doran, J.: Simulating Collective Misbelief, In: Journal of Artificial Societies and Social Simulation, Vol. 1, no. 1 (1998)

10. Folse, L., Packard J., Grant W.: AI modelling of animal movements in a heterogenous habitat. Ecological modelling. Vol. 46 (1989) 57-72

11. Greif, A.: Reputation and Coalitions in Medieval Trade: Evidence on the Maghribi Traders. In: The journal of economic history, Vol XLIX, no. 4 (1989) 857-882

12. Haddadi A., Sundermeyer K.: Belief-Desire-Intention Agent architectures. In: O'Hare and Jennings (eds), Foundations of Distributed Artificial Intelligence, Wiley InterSciences (1996)

13. Hardin, G: The tragedy of the commons. In: Science, Vol. 162 (1968) 1243-1248

14. North, D.C.: Institutions, institutional change and economic performance, Cambridge University Press, Cambridge (1990)

15. Ostrom, E.: Governing the commons. The evolution of Institutions for collective action. Cambridge University Press, Cambridge (1990) 
16. Requier-Desjardins, M.: L'accès aux pâturages, une approche économique de la mobilité, In: Actes du colloque Méga-Tchad, L'homme et l'animal dans le bassin du lac Tchad. Orstom, Paris (1997)

17. Rouchier, J., Barreteau, O., Bousquet, F.: Evolution and Coevolution of Individuals and Groups. In: Yves Demazeau (ed), Proceedings of the Third International Conference on Multi-Agent Systems, IEEE Los Alamitos, USA (1998) 254-260

18. Rouchier, J., Requier-Desjardins, M.: L'interdisciplinarité pour la modélisation dans la recherche-développement. Compte-rendu d'une experience en cours, une application au pastoralisme soudano-sahélien. Proceedings of SMAGET, Cemagref, Clermont-Ferrand (1998) 193-204

19. Rouchier, J., Bousquet, F., Requier-Desjardins, M., Antona, M.: A Multi-Agent model for describing transhumance in North Cameroon: comparison of different rationality to develop a routine. In: Journal for Economic Dynamic and Control, Vol. 25 (2001) 527-559

20. Takforyan, A.: La chasse : gestion communautaire et logique économique (Cameroun). In: Compagnon, D., Constantin, F. (eds), Karthala, Paris, Ifra, Nairobi (2000) 155-177

21. Williamson, O.E.: Les institutions de l'économie. Inter Editions, Paris (1994) 